\title{
Efficacy of Oral Exfoliative Cytology in Diabetes Mellitus Patients: A Light Microscopic and Confocal Microscopic Study
}

\author{
${ }^{1}$ Deepika Gopal, ${ }^{2} \mathrm{~N}$ Malathi, ${ }^{3} \mathrm{~B}$ Thirupathi Reddy
}

\begin{abstract}
Aim: Diabetes mellitus (DM) has become a global problem. By monitoring the health status of these individuals, diabetic complications can be prevented. We aimed to analyze alterations in the morphology and cytomorphometry of buccal epithelial cells of type 2 DM patients using oral exfoliative cytology technique and determine its importance in public health screening, diagnosis and monitoring of diabetes mellitus.
\end{abstract}

Materials and methods: The study was carried out in 100 type 2 DM patients and 30 healthy individuals. Smears were taken from the right buccal mucosa and stained by the Papanicolaou technique. Staining with Acridine orange was carried out to view qualitative changes with confocal laser scanning microscope (LSM-510 Meta). The cytomorphometry was evaluated using IMAGE PRO PLUS 5.5 software with Evolution LC camera. All findings were statistically analyzed.

Results: The results showed that with increase in fasting plasma glucose levels, there is significant increase in nuclear area, decrease in cytoplasmic area, and increase in nuclear cytoplasmic ratio $(p<0.05)$ when compared to the control group. Various qualitative changes were noted, such as cell degeneration, micronuclei, binucleation, intracytoplasmic inclusion, candida and keratinization.

Conclusion: In the present study, we found significant alterations in the cytomorphometry and cytomorphology of buccal epithelial cells of type 2 DM patients. This study supports and extends the view that these cellular changes can alert the clinician to the possibility of diabetes and aid in monitoring of diabetes throughout the lifetime of the patient.

Keywords: Confocal laser scanning microscope, Cytomorphometry, Diabetes mellitus, Oral exfoliative cytology.

How to cite this article: Gopal D, Malathi N, Reddy BT. Efficacy of Oral Exfoliative Cytology in Diabetes Mellitus Patients: A Light Microscopic and Confocal Microscopic Study. J Contemp Dent Pract 2015;16(3):215-221.

\footnotetext{
${ }^{1}$ Department of Oral Pathology, Penang International Dental College, Penang, Malaysia

${ }^{2}$ Department of Oral Pathology, Sri Ramachandra University Chenai, Tamil Nadu, India

${ }^{3}$ Department of Prosthetic Dentistry, Penang International Dental College, Penang, Malaysia

Corresponding Author: Deepika Gopal, Assistant Professor Department of Oral Pathology, Penang International Dental College, Penang, Malaysia, Phone: 0104651261, e-mail: drdeepikagopal@gmail.com
}

Source of support: Nil

Conflict of interest: None

\section{INTRODUCTION}

Diabetes mellitus (DM) is not a single disease entity but rather a group of metabolic disorders sharing the common underlying feature of hyperglycemia. Hyperglycemia results from defects in insulin secretion, insulin action or both. The chronic hyperglycemia and resultant metabolic deregulation of carbohydrate, fat and protein may be associated with secondary damage in multiple organ systems, especially the kidneys, eyes, nerves and blood vessels. ${ }^{1}$ Recent estimates indicate that the number of people with DM in 2010 is 285 million and is expected to be 438 million in 2030. The global prevalence rate is $6.6 \%$ in 2010 and is expected to rise to $7.8 \%$ in $2030 .{ }^{2}$

India leads the world with largest number of diabetic subjects earning the dubious distinction of being termed the 'diabetes capital of the world'. According to the Diabetes Atlas 2009 published by the International Diabetes Federation, the total number of people with diabetes in India is 50.8 million and is expected to rise to 87 million in $2030 .^{3}$ It can no longer be considered a disease of affluent nation alone, it has become a global problem, a major epidemic of the twentieth century, and one which shows no sign of abating. ${ }^{3}$

Diabetes mellitus is the leading cause of end-stage renal disease, adult-onset blindness and traumatic lower extremity amputations. The prevalence of DM is increasing sharply in the developing world as more people adopt a sedentary lifestyle, with India and China being the largest contributors to the world's diabetic load. ${ }^{2}$

Oral exfoliative cytology is a relatively simple and noninvasive clinical technique which has the potential to be developed as a routine investigation for screening of DM. It can be used chair-side during routine dental examination. ${ }^{4}$ The various alterations in the cytomorphology of the oral mucosa in diabetes and characterization of these changes give clinicians a more accurate image of what really happens during diabetes. So in our study, the cytomorphometric and cytomorphologic changes were compared according to the different glucose levels 
of diabetes. In addition to light microscope, we used confocal laser scanning microscope, to ascertain the various cytomorphologic changes seen under light microscope. It is possible that the degree of cellular change depends on the progression of diabetes. Hence, the present study was undertaken as this research area has received little attention to date.

\section{MATERIALS AND METHODS}

\section{Selection of Subjects}

The study was carried out in type 2 DM patients attending the diabetic outpatient department of General Medicine of Sri Ramachandra University, Chennai, India. These patients were under regular monitoring of blood sugar levels and subsequent treatment. The experimental group included 100 type 2 DM patients and the control group consisted of 30 healthy individuals free of any systemic diseases with clinically normal oral mucosa.

\section{Study Groups}

The entire study sample was grouped for statistical analysis, based on the recent fasting plasma glucose (FPG) levels as follows: group I: FPG 110-150 mg/dl; group II: FPG 150-200 mg/dl; group III: FPG > 200 mg/dl; control: FPG $<110 \mathrm{mg} / \mathrm{dl}$.

\section{Exclusion Criteria}

Individuals with habit of tobacco use in any form, habitual alcohol intake, any other systemic illness, clinically evident nutritional deficiencies like anemia, presence of oral sepsis were excluded from the study. After selection of the patient, informed consent was obtained and the procedure was carried out. In addition, the biochemical and hematological measurements were carried out to exclude anemia and other systemic disease.

\section{Smear Collection and Preparation}

Patients were asked to rinse their mouth to remove any debris. Following this, with a gentle scraping motion, cells were scraped from clinically normal appearing right buccal mucosa. The scrapings were then evenly smeared onto the glass slide and immersed in 95\% isopropyl alcohol in a coplin jar, for half an hour.

\section{Staining Technique}

Smears from all the samples were stained by the papanicolaou technique (PAP). For few samples two smears were taken from the same site, one stained using PAP and other using acridine orange (AO), a fluorescent dye, to view with confocal laser scanning microscope. In cases with very high plasma glucose levels smear was stained with periodic acid schiff (PAS) technique to assess presence of candida.

\section{Cytomorphometric Assessment}

The cytomorphometric analysis was done using IMAGE PRO PLUS 5.5 software with evolution LC camera. In each of the PAP stained slide, 10 fields were chosen by systematic sampling in a step wise manner, moving from left to right and then down and across in order to avoid measuring the same cells again. Cells with clearly defined cellular outlines were only chosen and those that were clumped, overlapped or folded were excluded for analysis. The cells were projected on to the monitor via the camera at 40× magnification and images were captured. In the software main menu, the function 'Measurement mode' was selected and the icon specifying 'polygon' was enabled to analyze the area of interest. The nuclear area (NA) and cytoplasmic area (CA) were obtained by drawing around the nuclear and cell boundaries using the cursor. The areas were recorded in square microns. The nuclear cytoplasmic ratio (N/C) was calculated for all the cells. The various parameters calculated were by the image analysis software, thereby reducing the subjective error.

\section{Cytomorphologic Assessment}

The PAP and PAS stained slides were viewed under light microscope whereas the AO stained slides were viewed under confocal laser scanning microscope (LSM-510 meta). Morphologic assessment included inflammatory component, cell degeneration, micronuclei, binucleation, intracytoplasmic inclusion, candida, keratinization, intracytoplasmic microorganisms and any other changes.

\section{RESULTS}

On comparison of the cytomorphometry between the various study groups, the results showed a significant increase in the NA and N/C ratio $(p<0.001)$ with increase in the level of FPG level. On the contrary, there was a significant decrease in the level of the CA $(p<0.004)$ with increase in the FPG level (Table 1). The results are shown with a line graph and representation of cell from each group in Figures $1 \mathrm{~A}$ to $\mathrm{F}$.

The qualitative changes in the different groups were analyzed statistically. For this the experimental group was divided into group A with a FPG less than $200 \mathrm{mg} /$ $\mathrm{dl}$ and group B with a FPG more than $200 \mathrm{mg} / \mathrm{dl}$. The Chi-square value and odds ratio were calculated (Table 2). We found that micronuclei (MN), presence of keratinization and cell degeneration was statistically significant. 

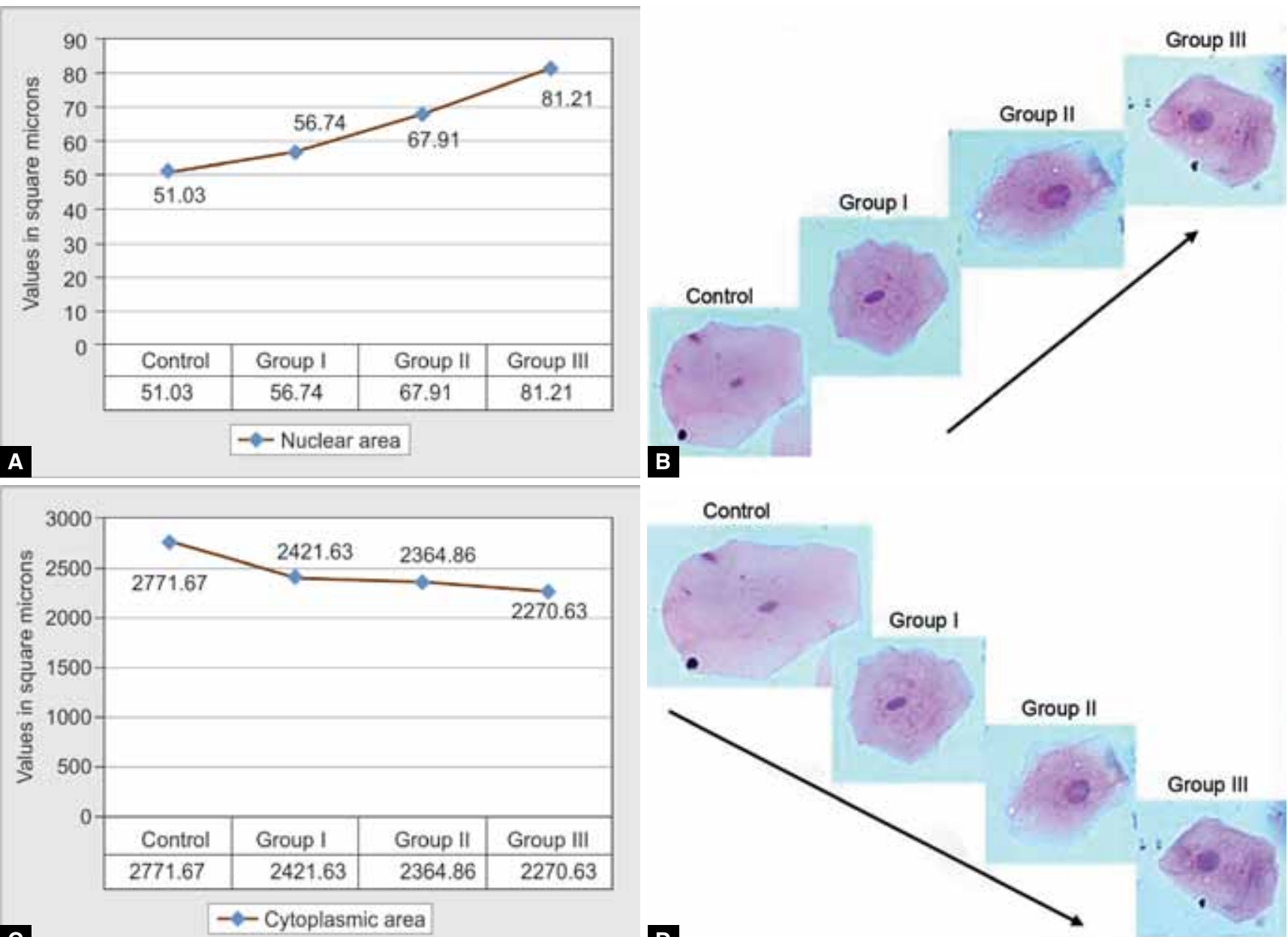

B

C
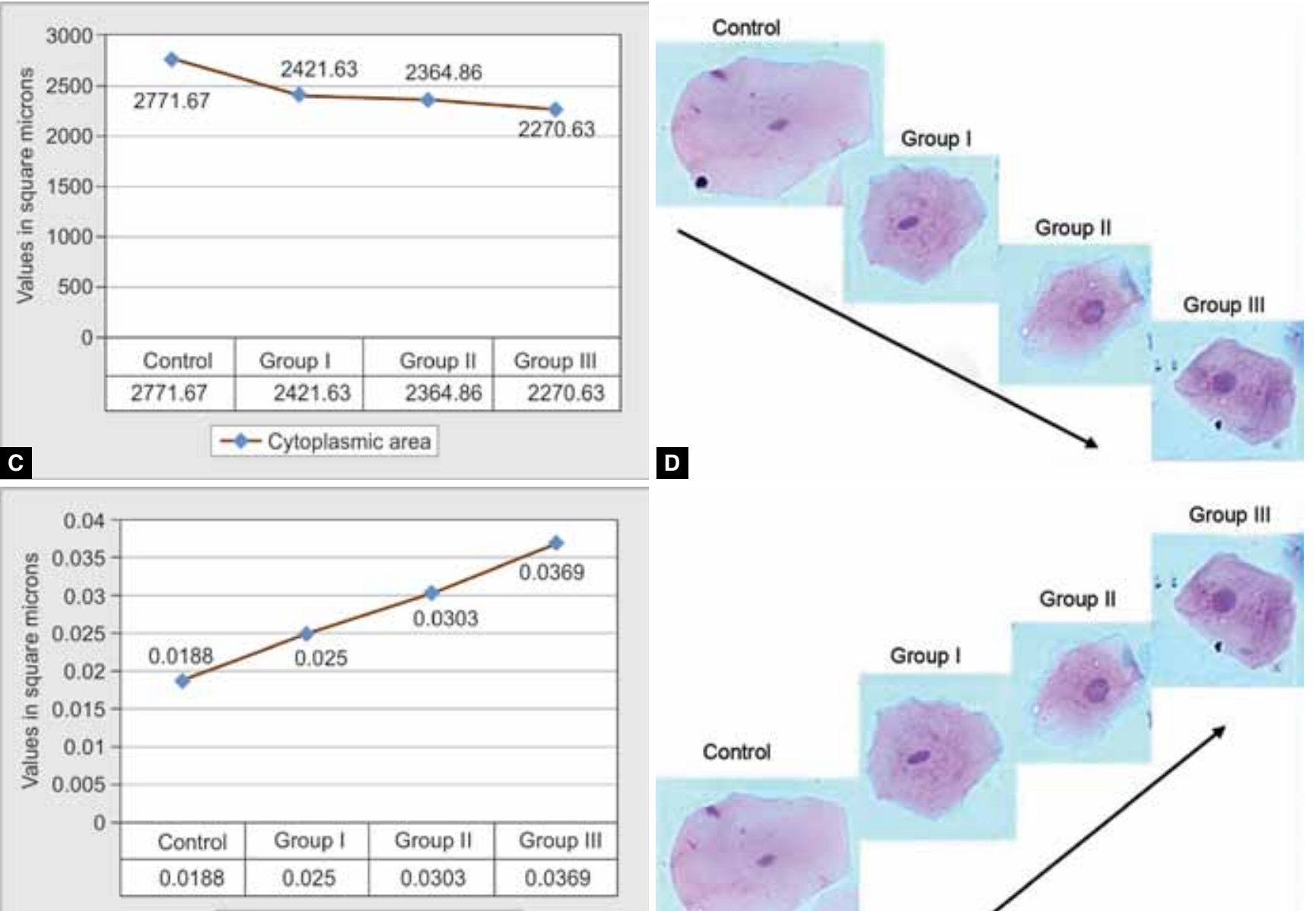

E

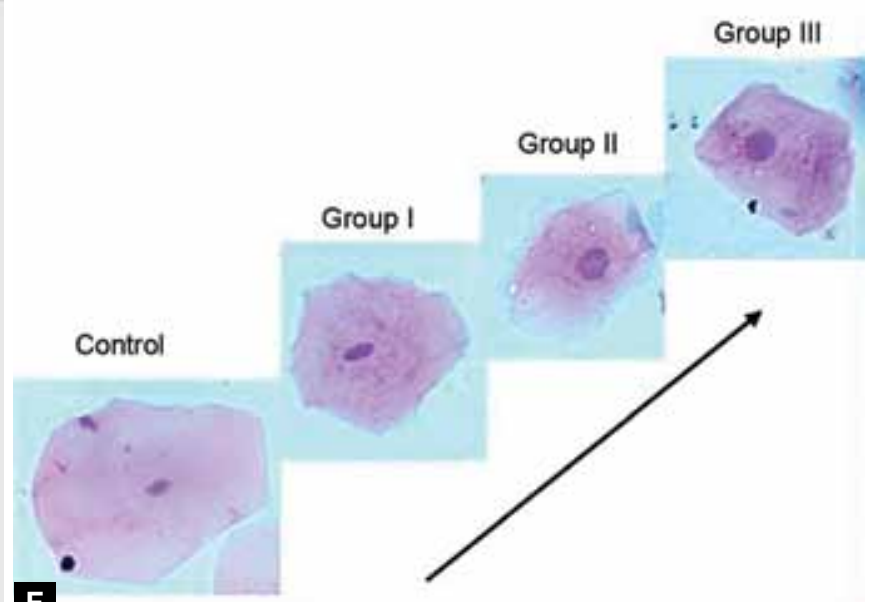

Figs 1A to F: (A) Line graph comparing the nuclear area between various groups, (B) a representation of cell from each group, (C) line comparing the cytoplasmic area between various groups, (D) a representation of cell from each group, (E) line graph comparing the nuclear cytoplasmic ratio between various groups and $(F)$ a representation of cell form each group

Increased numbers of polymorphonuclear leukocytes were observed in the study group than chronic inflammatory cells.

\section{DISCUSSION}

Diabetes mellitus has become a global problem. It is not a disease but a metabolic disorder. Early detection and subsequent monitoring of this disorder will definitely improve the health of individuals suffering from diabetes. By monitoring the health status of the individuals, diabetic complications leading to morbidity can be prevented, thus producing a healthy society. In the present study, we aimed to analyze alterations in the morphology and cytomorphometry of buccal mucosal cells of type 2 diabetics using exfoliative cytology technique and determine its importance in public health screening and monitoring of DM. 
Table 1: The mean and standard deviation of NA, CA, N/C ratio of experiment groups

\begin{tabular}{|c|c|c|c|c|c|}
\hline & Groups & $N$ & Mean & Standard deviation & $p$-value \\
\hline \multirow{3}{*}{${ }^{*} \mathrm{NA}\left(\mu \mathrm{m}^{2}\right)$} & Control & 30 & 51.0319 & 4.66957 & \multirow{4}{*}{$<0.001$} \\
\hline & I & 35 & 56.7402 & 6.56845 & \\
\hline & II & 32 & 67.9144 & 4.92782 & \\
\hline \multirow{5}{*}{${ }^{*} \mathrm{CA}\left(\mu \mathrm{m}^{2}\right)$} & III & 33 & 81.2142 & 10.97490 & \\
\hline & Control & 30 & 2771.6794 & 504.87645 & \multirow{4}{*}{0.004} \\
\hline & I & 35 & 2421.6397 & 633.84979 & \\
\hline & II & 32 & 2364.8695 & 551.06551 & \\
\hline & III & 33 & 2270.6325 & 554.82210 & \\
\hline \multirow{4}{*}{${ }^{*} \mathrm{~N} / \mathrm{C}$ ratio } & Control & 30 & 0.018874 & 0.0031945 & \multirow{4}{*}{$<0.001$} \\
\hline & I & 35 & 0.025061 & 0.0074491 & \\
\hline & II & 32 & 0.030308 & 0.0074751 & \\
\hline & III & 33 & 0.036975 & 0.0064759 & \\
\hline
\end{tabular}

*(NA: Nuclear area, CA: Cytoplasmic area, N/C: Nuclear cytoplasmic ratio) FPG: Fasting plasma glucose; Control: FPG < 110 mg/dl, Group I: FPG = 110-150 mg/dl; Group II: FPG = 150-200 mg/dl; Group III: FPG >200 mg/dl Table 1 shows there is increase in the level of mean value of NA \& N/C ratio with increase in the level of FPG (statistically significant $p<0.001$ ) and a decrease in the level of mean value in the CA with increase in the FPG level (statistically significant $p<0.004$ )

Table 2: Statistical analysis of various qualitative changes in the experiment groups

\begin{tabular}{|c|c|c|c|c|c|c|c|c|c|}
\hline \multirow[b]{2}{*}{ Groups } & \multicolumn{2}{|c|}{$\begin{array}{c}A \\
\# F P G<200 \mathrm{mg} / \mathrm{dl}\end{array}$} & \multicolumn{2}{|c|}{$\begin{array}{c}B \\
\# F P G>200 \mathrm{mg} / \mathrm{dl}\end{array}$} & \multirow{2}{*}{$\begin{array}{l}\text { Chi-square } \\
\text { value }\end{array}$} & \multirow[b]{2}{*}{ Odds ratio } & \multirow[b]{2}{*}{$p$-value } & \multicolumn{2}{|c|}{ Percentage } \\
\hline & Present & Absent & Present & Absent & & & & $A$ & $B$ \\
\hline Micronuclei & 24 & 43 & 20 & 13 & 5.51 & 0.36 & $0.018^{*}$ & 35.82 & 60.6 \\
\hline Cell degeneration & 25 & 42 & 19 & 14 & 3.68 & 0.44 & $0.05^{*}$ & 37.31 & 57.57 \\
\hline Binucleation & 28 & 39 & 17 & 16 & 0.84 & 0.68 & 0.35 & 41.79 & 51.51 \\
\hline Keratinization & 18 & 49 & 16 & 17 & 4.67 & 0.39 & $0.031^{*}$ & 26.86 & 48.48 \\
\hline Microorganisms & 15 & 52 & 11 & 22 & 1.38 & 0.58 & 0.24 & 22.38 & 33.33 \\
\hline Inflammatory cells & 29 & 38 & 16 & 17 & 0.24 & 0.81 & 0.62 & 43.28 & 48.48 \\
\hline Candida & 5 & 62 & 5 & 28 & 1.45 & 0.45 & 0.22 & 7.46 & 15.15 \\
\hline Intracytoplasmic inclusion & 36 & 31 & 18 & 15 & 0.01 & 0.97 & 0.93 & 53.73 & 54.54 \\
\hline
\end{tabular}

(\#FPG: Fasting plasma glucose; *p-value-significant) Group A: FPG < $200 \mathrm{mg} / \mathrm{dl}$ and Group B: FPG $>200 \mathrm{mg} / \mathrm{dl}$. The Chi-square value and odds ratio were calculated. Table 2 shows that micronuclei, presence of keratinization and cell degeneration was statistically significant

The study showed a significant steady increase in NA with increase in blood sugar level (Figs 1A to E) from control group (Mean NA-51.03 $\mu^{2}$ ) to the diabetic Group III (Mean NA-81.21 $\mathrm{mm}^{2}$ ). This finding concurs with other previously reported studies who reported a significant increase in NA in diabetic patients. ${ }^{5-7}$ However, all these studies did not categorize the patients based on the blood glucose levels. Similar studies using cytomorphometry have been done to analyze the effect of alcohol, tobacco, radiotherapy on buccal mucosa. ${ }^{8-12}$ The nucleus contains the genomic DNA, histones and several proteins. The nuclear size can, therefore, be altered by change in the content of DNA or proteins. There is usually twice as much protein as DNA in a nucleus. ${ }^{13}$ Hyperglycemia induces a compensatory increase in insulin secretion which in turn causes increase in protein formation. Insulin has several mitogenic functions, including initiation of DNA synthesis in certain cells. These may account for the increase in NA seen in diabetes patients. ${ }^{14}$

Our study revealed a decrease in CA with increase in blood sugar level, i.e. group III mean CA was 2270.63 $\mu \mathrm{m}^{2}$ and control mean CA was $2771.6 \mu \mathrm{m}^{2}$ (Figs 1A to E). This finding is contradictory to studies by Alberti et $\mathrm{al}^{5}$ and Shareef et $\mathrm{al}^{6}$ who found that CA did not show any significant difference in diabetics and Hassan et al $^{7}$ who reported a significant increase in CA. However, this finding concurs with Prasad et $a{ }^{15}$ who reported a decrease in cell diameter and cytoplasmic diameter with increase in glycemic status. Ogden et $\mathrm{a} \mathrm{l}^{10}$ have reported a similar reduction in cell diameter in patients with habit of alcoholism. The reduction in CA in our study could be due to the dehydrated condition of the diabetics. Increased blood glucose causes dehydration, polyuria, polydipsia, intracellular and extracellular dehydration. Glucose does not diffuse easily through the pores of the cell membrane causing an increase in osmotic pressure. This increase in osmotic pressure in extracellular fluid causes osmotic transfer of water out of the cells explaining the reduction in CA. ${ }^{16}$

The comparison of N/C ratio between control and experiment groups showed a steady increase in N/C ratio (from Control-0.0188 to Group III-0.0369) with increasing 


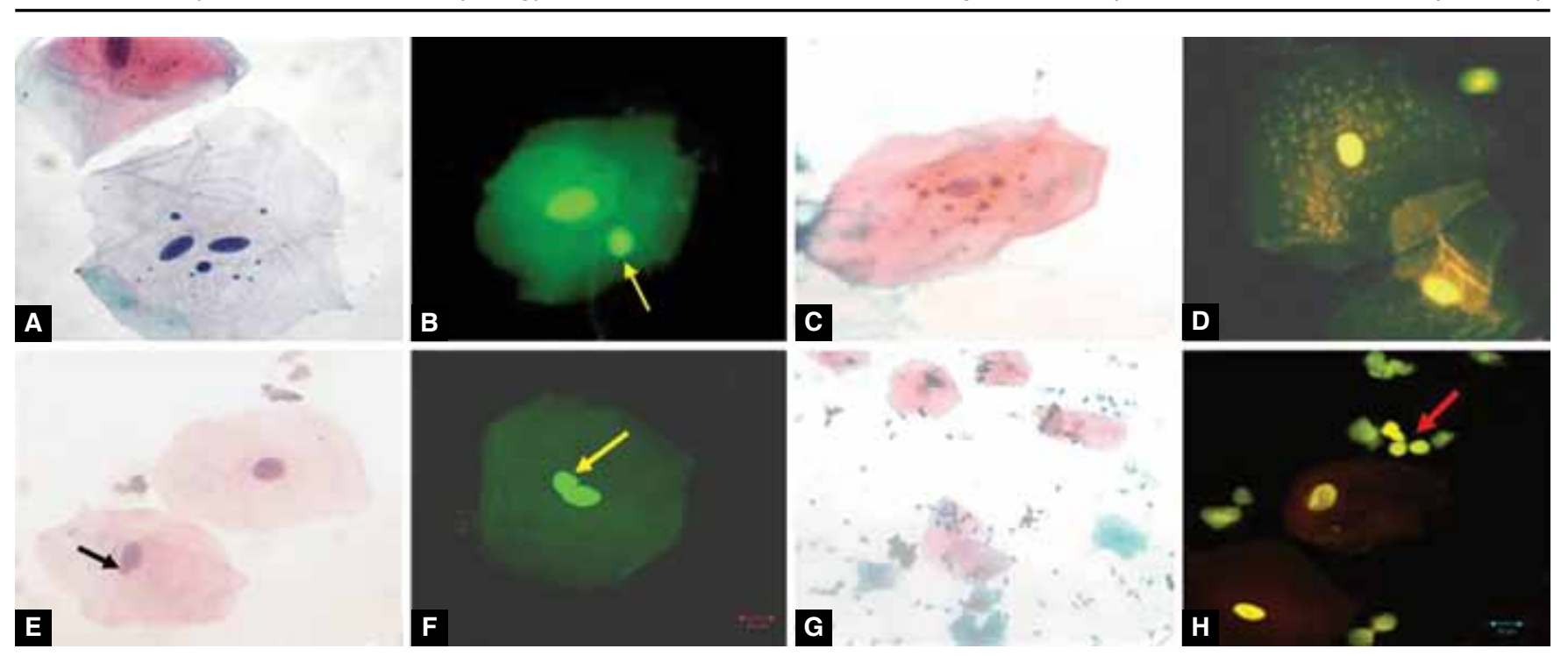

Figs 2A to H: Micronuclei viewed under light microscope (PAP stain 40x) and under confocal microscope (AO stain, 100x) (A and B); intracytoplasmic inclusions seen under light microscope (PAP stain 40x) and under confocal microscope (AO stain 100x), (C and D); nuclear bud formation viewed under light microscope (PAP stain,40x) and under confocal microscope (AO stain,100x), (E and F); inflammatory cells under light microscope (PAP stain 20x) and under confocal microscope(AO stain 40x) (G and H)

blood glucose levels (Figs 1A to F). This may be due to a real increase in NA and decrease in CA in diabetic patients, rather than just a deviation from normal. This finding concurs with Rivera and Nunez de-Mendoza ${ }^{17}$ and Prasad et a ${ }^{15}$ who also reported increase in N/C ratio.

In the qualitative changes, we found that $(\mathrm{MN}) \mathrm{Mi}-$ cronucles was present in 44 cases which was statistically significant $(p=0.018)$. Micronucles are known biomarkers of genome damage and has been studied in buccal cell systems. They provide a convenient and reliable index of both chromosome breakage and chromosome loss. Micronucles is found in cells that have completed nuclear division. Micronucles was judged according to criteria by Holland et al. ${ }^{18}$ Another biomarker of genome damage is nuclear bud formation which was also visualized but not statistically analyzed. ${ }^{16}$ The nuclear bud has the same morphology and staining properties as the nucleus, however, its diameter may range from a half to a quarter of that of the main nucleus. Hyperglycemia results in formation of Advanced Glycation End products (AGE), endothelial nitric oxide synthase uncoupling, activation of protein kinase $C$ and activation of polyol pathway. This in turn causes activation of reactive oxygen species which results in induction of oxidative stress. Oxidative stress is an imbalance between the production of reactive oxygen species and the biological systems ability to readily detoxify the reactive intermediates or to repair the resulting damage. The effects of oxidative stress depend upon the size of these changes, wherein a cell can overcome small perturbations and regain its original state. However, more severe oxidative stress can cause cell death and even moderate oxidation can trigger apoptosis, while more intense stresses may cause necrosis. Oxida- tive stress has been found to cause genomic damage in DM. ${ }^{19}$ This supports the observation of $\mathrm{MN}$ in diabetic patients. Few other studies also showed increase in MN in lymphocyte cultures of type 2 diabetics. ${ }^{20,21}$

This is the first reported study in which an attempt has been made to study qualitative changes of buccal smear using confocal microscopy. The use of fluorescence dye (Acridine Orange) and visualization under confocal laser scanning microscope enhanced the demonstration of nuclei and micronuclei. They also helped to avoid false positive results.

Statistical analysis revealed that cell degeneration was present in 44 cases out of 100 cases. It was statistically significant $(p=0.05)$ implying that increase in blood glucose level leads to oxidative stress and showed increase in degeneration and necrosis. The various qualitative changes included karyorrhexis, pyknosis, apoptosis and chromatin abnormalities. Previous studies by Alberti et $\mathrm{al}^{5}$ and Shareef et $\mathrm{al}^{6}$ also demonstrated qualitative changes of karyorrhexis. Another significant qualitative change found was the presence of keratinization. This finding is in accordance with an earlier study by Zimmermann and Zimmermann ${ }^{22}$ who stated that endocrine disorders like DM had increased keratinized cell count in the buccal mucosa. The increase in this keratinization may be a compensation for decreased salivary flow. ${ }^{5}$ Binucleation was present in 45 cases out of 100 but showed no statistically significant result. The significance of these binucleate cells is unknown, but they are probably indicative of failed cytokinesis following the last nuclear division in the basal cell layer. Studies by Alberti et $\mathrm{al}^{5}$ and Shareef et $\mathrm{al}^{6}$ also showed similar findings of binucleation. Increased number of polymorphonuclear leukocytes was observed 


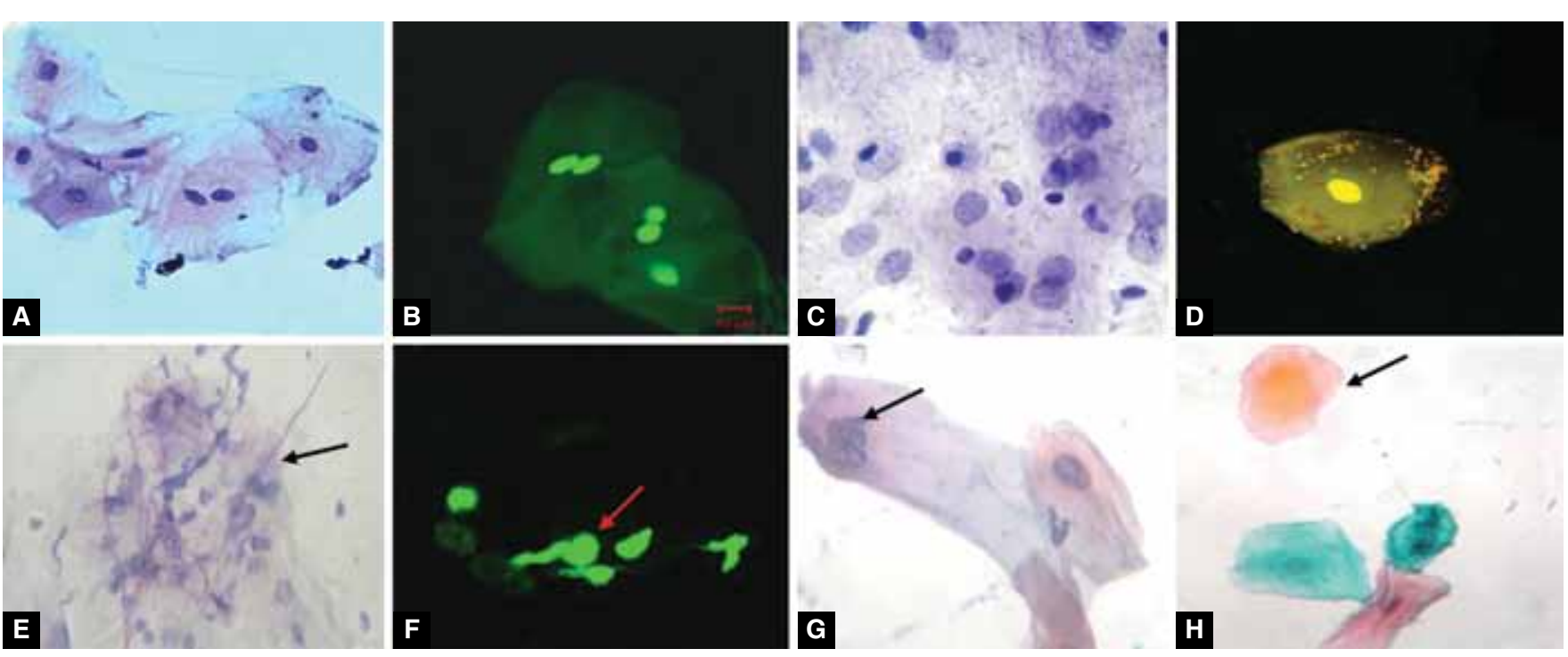

Figs 3A to H: Binucleation viewed under light microscope (PAP stain 40x) and under confocal microscope (AO stain 40x) (A and B); Shows microorganisms viewed under light microscope (PAS stain 100x) and under confocal microscope (AO stain 40x) (C and D); Candida seen under light microscope (PAS stain 40x) and under confocal microscope (AO stain 100x) (E and F); cell with feature of cell degeneration seen under light microscope (PAP stain 40x) (G); keratinized cell seen under light microscope (PAP stain 40x) (H)

in the experiment group than chronic inflammatory cells. Increase in inflammation could be due to decreased salivary flow found in diabetics owing to hypofunction of the salivary glands. Jajarm et $\mathrm{al}^{7}$ in their study found that incidence of inflammation was higher in diabetic smears. Figures 2 and 3 show the various qualitative changes viewed under light microscope and confocal scanning microscope.

\section{CONCLUSION}

From our study, we could conclude that diabetes produces significant alterations in the cytomorphometry and cytomorphology of buccal epithelial cells. The use of confocal laser scanning microscopy demonstrated qualitative changes with higher resolution and clarity and helped in reducing the possibility of recording false positive and/or false negative observations.

\section{CLINICAL SIGNIFICANCE}

Oral exfoliative cytology is helpful in diabetic patients who have aversion and fear to needle pricks as it is painless and can be carried out regularly. The minimal time and ease of the procedure is beneficial in mass screening and public health awareness programme. Though it may not be used as a diagnostic tool, they can aid in monitoring of DM throughout the lifetime of the patient, thereby decreasing the morbidity and preventing longterm complications.

\section{ACKNOWLEDGMENT}

The authors would like to thank the Central Research Facility and Department of General Medicine of Sri
Ramachandra University, Chennai. The authors would also like to thank the laboratory technician, Department of Oral Pathology and statistician for their valuable contribution in the study.

\section{REFERENCES}

1. Kumar V, Abbas KA, Fausto N. Robbins and Cotran. Pathologic basis of disease. 8th edn. Philadelphia: Saunders 2010.

2. International Diabetes Federation. IDF Diabetes Atlas. 4th ed. Brussels, Belgium: International Diabetes Federation, 2009.

3. King H, WHO and Diabetes, World Health, 1991 May-Jun;3.

4. Saraswati TR. Oral exfoliative cytology. Monograph published at National PG conventions, IAOMP, Chennai; 2002.

5. Alberti S, Spadella CT, Francischone TR, Assis GF, Cestari TM, Taveira LA. Exfoliative cytology of the oral mucosa in type II diabetic patients: morphology and cytommorphometry. J Oral Pathol Med 2003;32(9):538-543.

6. Shareef BT, Ang KT, Naik VR. Qualitative and quantitative exfoliative cytology of normal oral mucosa in type 2 diabetic patients. Med Oral Patol Oral Cir Bucal 2008;13(11):E693-696.

7. Jajarm HH, Mohtasham N, Rangiani A. Evaluation of oral mucosa epithelium in type II diabetic patients by an exfoliative cytology method. J Oral Sci 2008;50:335-340.

8. Ogden GR, Cowpe JG, Green MW. Effect of radiotherapy on oral mucosa assessed by quantitative exfoliative cytology. J Clin Pathol 1989;42:940-943.

9. Ogden GR, Cowpe JG, Green MW. Quantitative exfoliative cytology of normal buccal mucosa: effect of smoking. J Oral Pathol Med 1990 Feb;19(2):53-55.

10. Ogden GR, Wight AJ, Cowpe JG. Quantitative oral exfoliative cytology. Effect of alcohol on normal buccal mucosa. Anal Quant Cytol Histol 1999;21(2):126-130.

11. Ramaesh T, Mendis BR, Ratnatunga N, Thattil RO. The effect of tobacco smoking and of betel chewing with tobacco on the buccal mucosa: a cytomorphometric analysis. J Oral Pathol Med 1999 Oct;28(9):385-388. 
12. Einstein TB, Sivapathasundharam B. Cytomorphometric analysis of the buccal mucosa of tobacco users. Indian J Dent Res 2005 Apr-Jun;16(2):42-46

13. Bibbo M, David W (2008) Comprehensive cytopathology. 3rd ed. Philadelphia: W.B Saunders and company.

14. Guyton AC, Hall HE. Textbook of medical physiology. 11th ed. Philadelphia: Elsevier Saunders 2006.

15. Prasad H, Ramesh V, Balamurali P. Morphologic and cytomorphometric analysis of exfoliated buccal mucosal cells in diabetes patients. J Cytol 2010;27:113.

16. Thomas P, Harvey S, Gruner T, Fenech M. The buccal cytome and micronucleus frequency is substantially altered in Down's syndrome and normal ageing compared to young healthy controls. Mutat Res 2008 Feb 1;638(1-2):37-47.

17. Rivera C, Núñez-de-Mendoza CC. 'Exfoliative cytology of oral epithelial cells from patients with type 2 diabetes: cytomorphometric analysis. Int J Clin Exp Med 2013;6(8): 667-676.
18. Holland N, Bolognesi C, Kirsch-Volders M, Bonassi S, Zeiger E, Knasmueller S, Fenech M. The micronucleus assay in human buccal cells as a tool for biomonitoring DNA damage: the HUMN project perspective on current status and knowledge gaps. Mutat Res 2008 Jul-Aug;659(1-2):93-108.

19. Colledge NR, Walker BR, Ralston SH. Davidson's Principles and Practice of Medicine. 21st ed. Edinburgh Churchill Livingstone: Elsevier 2009.

20. Shettigar SK, Shailaja C, Kulkarni RK. Elevated micronuclei frequency in type 2 diabetes with high glycosylated hemoglobin. Diabetes Res Clin Pract 2012 Feb;95(2):246-250.

21. Martínez-Pérez LM, Cerda-Flores RM, Gallegos-Cabriales EC, Dávila-Rodríguez MI, Ibarra-Costilla E, Cortés-Gutiérrez E. I. Frequency of micronuclei in Mexicans with type 2 diabetes mellitus. Prague Med Rep 2007;108:248-255.

22. Zimmermann ER, Zimmermann AL. Effects of race, age, smoking habits, oral and systemic disease on oral exfoliative cytology. J Dent Res 1965 Jul-Aug;44:627-631. 